\title{
The inevitability and irreversibility of organizational uncontrollability
}

\author{
Hugh van der Mandele ${ }^{1}$ Arjen van Witteloostuijn ${ }^{1,2}$
}

(c) The Author(s) 2015. This article is published with open access at Springerlink.com

\begin{abstract}
In this paper, a classic and seminal contribution of Williamson (J Polit Econ 75:123-138, 1967), "Hierarchical control and optimum firm size", is revisited so as to remove two of its restrictive assumptions. The introduction of the dynamics of the quality of vertical communication into Williamson's static model and the development of a simulation to analyze these dynamics provide the opportunity to demonstrate the plausibility of a new conjecture: in each and every hierarchically structured organization, irreversible organizational uncontrollability is ultimately bound to arise, even in a completely stable environment. This is our main contribution. Moreover, we demonstrate that this conjecture is also valid for non-hierarchically structured organizations.
\end{abstract}

Keywords Control loss · Uncontrollability - Serial reproduction · Organizational failure $\cdot$ Simulation $\cdot$ Stochastic logistic equation

\section{Introduction}

In a classic and seminal article, Williamson (1967) demonstrated the plausibility that "the cumulative effects of control loss are fundamentally responsible for limitations in firm size" (1967, p. 130). By way of introduction, Williamson used a seemingly incidental but very insightful remark made by Boulding at a lecture for

\footnotetext{
The paper is an extensively revised and improved version of Chapter 7 of our book Free to Fail: Creative Destruction revisited (2013). Section 3 briefly summarizes the outcomes of a computer simulation that is based on joint work with César García-Díaz.
}

Arjen van Witteloostuijn a.vanwitteloostuijn@uvt.nl

1 IWACO, Tilburg University, Tilburg, The Netherlands

2 Antwerp Management School, Antwerp, Belgium 
the Annual Meeting of the American Economic Association (Boulding 1966, p. 8): "There is a great deal of evidence that almost all organizational structures tend to produce false images in the decision-maker, and that the larger and more authoritarian the organization, the better the chance that its top decision-makers will be operating in purely imaginary worlds. This perhaps is the most fundamental reason for supposing that there are ultimately diminishing returns to scale." Using a model prepared for this purpose, Williamson demonstrated the plausibility of Boulding's statement. In so doing, he introduced the key concept of control, defined as "the fraction $\alpha$ of the intentions of a superior effectively satisfied by a subordinate $(0<\alpha<1)$ " (Williamson 1967, p. 127). ${ }^{1}$

In the current article, we reinterpret and enrich Williamson's (1967) analysis by removing two of its restrictive assumptions. The introduction of the dynamics of the quality of vertical communication into Williamson's static model and the development of a simulation to analyze these dynamics provide the opportunity to demonstrate the plausibility of a second conjecture: in each and every hierarchically organized firm, irreversible organizational uncontrollability is ultimately bound to arise. ${ }^{2}$ Moreover, we demonstrate that this conjecture is also valid for non-hierarchically structured organizations. On the basis of our findings, we argue that the theory of the firm can and should be enriched by developing an information exchange imperfection perspective on organizational functioning.

Specifically, in order to eliminate the first restriction-the model being static instead of dynamic - we introduce a time dimension in a new mathematical model that focuses on the dynamics of the quality of vertical communication. We carry out a computer simulation with this model (a stochastic logistic equation). The result transcends Williamson's analysis in offering a rationale not only for his own conjecture, but also for the conjecture that in each and every hierarchically organized firm irreversible organizational uncontrollability is ultimately bound to arise, even in a completely stable environment. We define uncontrollability as the situation in which control has fallen below a certain level such that the superior cannot take any effective remedial action because, for lack of relevant information, diagnosis is not possible.

A second restriction implied by Williamson is that he models hierarchically structured organizations. We will demonstrate that adapting our analysis to organizations that are non-hierarchical-that is, in which participants are given more leeway by the superior in deciding appropriate courses of action-requires only limited reformulation of our model. The results of our analysis are identical: organizational uncontrollability is still ultimately bound to arise, for both hierarchies and non-hierarchies. But before doing all this, we will first carefully

\footnotetext{
${ }^{1}$ Confusingly, Tannenbaum (1962, p. 237) and later authors such as Leifer and Mills (1996) used the word "control" for the process, and not for the end result. In their vocabulary, we probably would have been using a term such as "control effectiveness percentage" where we join Williamson in using the term "control". Interestingly, where these authors describe "control loss" and "loss of control" meanings roughly coincide.

${ }^{2}$ We by no means suggest that uncontrollability is the only cause of organizational failure. The reader is referred to, for example, Stinchcombe (1965), Hannan and Freeman (1977, 1984), Miller (1990), Levitt and March (1988) and Sorge and van Witteloostuijn (2004) for complementary arguments.
} 
introduce Williamson's (1967) argument. We will do so by extensively quoting his original analysis. After all, we would not be able to introduce his logic more clearly and lucidly than he could himself-far from that.

\section{The concept of control}

It is entirely appropriate to start with a quotation by Coase, who laid the proverbial foundation stone for the transaction cost "school" in his Coase (1937) masterpiece "The Nature of the Firm". In this school's approach to organizations, the idea is emphasized that the essence of an organization lies in the fact that its participants no longer enjoy complete freedom of action. The transaction cost school studies the merits and demerits of transferring authority into the hands of a boss, who makes decisions after uncertainties regarding the environment have been resolved. Or, in the words of Coase (1937, p. 39):

At this stage it is important to note the character of the contract into which a factor enters that is employed in a firm. The contract is one whereby the factor, for a certain remuneration (which may be fixed or fluctuating), agrees to obey the directions of an entrepreneur within certain limits (italics in the original; underlining added).

Simon formalized this thought as follows:

The authority relationship that exists between an employer and an employee, a relationship created by the employment contract, will play a central role in our theory. What is the nature of the relationship? We will call our employer $B$ (for "boss"), and our employee $W$ (for "worker"). The collection of specific actions $W$ performs on the job (typing and filing certain letters, laying bricks, or what not) we will call his behavior. We will consider the set of all possible behavior patterns of $W$ and we will let $x$ designate an element of this set. A particular $x$ might then represent a given set of tasks, performed at a particular rate of working, a particular level of accuracy, and so forth. We will say that $B$ exercises authority over $W$ if $W$ permits $B$ to select $x$. That is, $W$ accepts authority when his behavior is determined ${ }^{3}$ by $B$ 's decision. In general, $W$ will accept authority only if $x_{0}$, the $x$ chosen by $B$, is restricted to some given subset ( $W$ 's "area of acceptance") of all the possible values. This is the definition of authority that is most generally accepted in modern administrative theory (1951, pp. 293-294; emphases in original).

The definition of an organization as "a number of people connected by authority relationships", or - in a more formal vocabulary - "a nexus of agency relations that can be represented by an authority chart" would fit perfectly in Simon's and Williamson's analysis. They analyzed hierarchical organizations with well-defined authority lines, or —in a more military language_ chains of command. Many others,

\footnotetext{
3 Later analysis, starting of course with Williamson's article, showed the phrase "when his behavior is determined by B's decision" to be too absolute.
} 
however, took a different track, studying the conformity of workers' actions with management instructions-or, in a less hierarchical context, conformity to "the rational of the organization" (Tannenbaum 1962, p. 237). They describe organizations as, for instance, "bargaining and influence systems" (Abell 1975, 1977). Still others focus on information processing and its dependence on motivational situations, cognitive abilities and quantitative limitations (Leifer and Mills 1996; Keren and Levhari 1989).

The track Williamson chose was to emphasize information transmission. This emphasis by no means contradicts these other arguments, but should be regarded as complementary. His analysis can be summarized as follows. Management of the firm is required to make the appropriate decisions in adapting to new circumstances, externally or internally: requesting the relevant data from the shop floor, processing the information supplied, and providing the appropriate instructions that are transferred directly or indirectly to the workers at the shop floor. Because the number of workers is too large to be managed by one manager, one or more hierarchical layers are interposed between the top manager and the shop floor. The number of intermediate layers will depend on the number of workers on the shop floor, and the number of workers that can be handled by one (intermediate) manager (i.e., her/his span of control).

Hierarchical organization involves vertical transmission of information: downwards, in the sense that instructions are passed from management to the shop floor and that information is demanded from the shop floor; and upwards, as data are either delivered from the shop floor to management on demand or spontaneously passed from the shop floor to management. The main question now becomes what the consequences are of the addition of hierarchical layers on the level of control. In his seminal article, rightly titled "Hierarchical control and optimum firm size", Williamson described the mechanism by which (lack of) control is influenced by the number of hierarchical layers lucidly:

The aspect of bureaucratic theory that we regard as particularly relevant for studying the question of a static limitation to firm size is what we will refer to as the "control loss" phenomenon. It is illustrated daily in the rumortransmission process and has been studied intensively by Bartlett $(1920,1932)$ in his experimental studies of serial reproduction. His experiments involved the oral transmission of descriptive and argumentative passages through a chain of serially linked individuals. Bartlett concludes from a number of such studies that: 'It is now perfectly clear that serial reproduction normally brings about startling and radical alterations in the material dealt with. Epithets are changed into their opposites; incidents and events are transposed; names and numbers rarely survive intact for more than a few reproductions; opinions and conclusions are reversed-nearly every possible variation seems as if it can take place, even in a relatively short series. At the same time the subjects may be very well satisfied with their efforts, believing themselves to have passed on all important features with little or no change, and merely, perhaps, to have omitted unessential matters.' Bartlett illustrates this graphically with a line drawing of an owl which-when redrawn successively by eighteen 
individuals, each sketch based on its immediate predecessor-ended up as a recognizable cat; and the further from the initial drawing one moved, the greater the distortion experienced. The reliance of hierarchical organizations on serial reproduction for their functioning thus exposes them to what may become serious distortions in transmission (1967, p. 126). ${ }^{4}$

This characteristic of serial reproduction was confirmed recently by Roediger et al. (2014, p. 2): "In sum, virtually every experiment we can find using Bartlett's serial reproduction technique [including Roedigeŕs experiments: HvdM and AvW] confirms his observations that social transmission of information is error prone and that the more links there are in the chain, the greater the probability of error" (comment added). Serial reproduction involves four iterative steps: (1) formulation; (2) transmittal; (3) reception; and (4) remembering (and then back to formulation). In each step, alteration (garbling) can and usually will occur. These alterations can consist of omission, addition and/or content change. For example, the information provided by a subordinate to a superior might be ambiguously formulated, leaving room for different interpretations at the superior's side, feeding a misinterpretation into the superior's memory. This information can involve anything work-related, from competitive business intelligence and cost accounting information to stock inventory data to product quality metrics. Comparable alteration can occur when an instruction reaches a subordinate. The key is that whatever the nature of the information or instruction, part of the message will be garbled-however Epsilon small-in the exchange. In fact, as Stinchcombe (2001, p. 1) argues, even formal texts (formulated in such a way that garbling is minimized) are still subject to misinterpretation and misrepresentation. "I will try to remind the reader from time to time that I do not believe that formality always works."

\section{Williamson continues by arguing that}

Downs has since elaborated the argument and summarized it in his "Law of Diminishing Control: 'the larger any organization becomes, the weaker is the control over its actions exercised by those at the top' (1966, p. 109). The cumulative loss of control as instructions and information are transmitted across successive hierarchical levels is responsible for this result. Thus, assuming that economies of specialization have been exhausted and that superiors are normally more competent than subordinates, a quality-quantity

\footnotetext{
${ }^{4}$ Interestingly, Marris and Mueller (1980, p. 39) reject this argument. In developing an extremely elegant model, they define $X_{L}$ as representing a message received at level $L$ purporting to be a message from $L+1$. If the message is not correctly received or is misinterpreted, there is an error $\left(X_{L}-X_{L+1}\right)$. They assume the possible correlation between the error and the message most generally to be expressed by the regression equation:

$\left(X_{L}-X_{L+1}\right)=(\beta-1) X_{L+1}+\mu_{L}$.

Marris and Mueller then state that "with effective monitoring $\beta$ could be less than one." This implies that a copy can more faithfully reflect the original than the original itself. No amount of monitoring can ever achieve that. Unfortunately, the remainder of their model, elegant as it is, rests on this misconception. Their result (that, according to their model, organizations can grow infinitely without losing efficiency) must therefore be rejected.
} 
trade-off necessarily exists in every decision to expand. It arises for two reasons, both of which are related to the distance of the top executive from the locus of productive activity. First, expansion of the organization (adding an additional hierarchical level) removes the superior further from the basic data that affect operating conditions; information regarding these conditions must now be transmitted across an additional hierarchical level which exposes the data to an additional serial reproduction operation with its attendant losses. Furthermore, the top executive cannot have all the information that he had before the expansion plus the information now generated by the new parts (assuming that he was fully employed initially). Thus, he can acquire additional information only by sacrificing some of the detail provided to him previously. Put differently, he trades off breadth for depth in undertaking the expansion; he has more resources under his control, but the quality (serial reproduction loss) and the quantity (phenomenon capacity constraint) of his information are both less with respect to the deployment of each resource unit. In a similar way, being further removed from the operating situation and having more subordinates means his instructions to each are less detailed and are passed across an additional hierarchical level. For precisely the same reasons, therefore, the behavior of the operating units will scarcely correspond as closely to his objectives as it did prior to the expansion. Taken together, this loss in the quality of data provided to the peak coordinator and in the quality of the instructions supplied to the operating units made necessary by the expansion will be referred to as "control loss". It will exist even if the objectives are perfectly consonant with those of their superiors, and a fortiori, when subordinate objectives are dissonant (1967, pp. 126-127; emphasis in original).

In elaborating upon his basic model, Williamson assumed that control loss is strictly cumulative across hierarchical layers, and that there is no systematic compensation. ${ }^{5}$ This assumption is reasonable. If, for instance, $90 \%$ of the instructions from the super-boss reaches the boss reliably, and $10 \%$ is garbled, the assumption that these latter instructions by the super-boss will ever reach the worker correctly would seem odd. Of the former, a certain percentage (say, $5 \%$ ) will become garbled during transmission from the boss to the worker, and $95 \%$ will be transferred correctly. This would mean that $0.95 * 0.90=85.5 \%$ of the original instructions would arrive at the worker undamaged, implying a cumulative control loss of $14.5 \%$. With each new hierarchical level, a new factor is inserted in the garbling multiplication, making the information transmitted across hierarchical layers more and more imperfect.

Of course, the number of hierarchical layers is not only determined by the number of workers, but also by the span of control of each manager, being the

\footnotetext{
5 Again, he is contradicted by Marris and Mueller, who argue that cumulative errors increase linearly with the length of the chain of command (Marris and Mueller 1980, p. 38). This is illogical. Assuming a certain constant percentage of correct transmission at each stage, it is obvious that this percentage only affects data correctly transmitted, and not data incorrectly transmitted.
} 
number of subordinates she manages. ${ }^{6}$ If each "boss" manages ten workers and each "super-boss" manages ten bosses, then a hundred workers will be led by one super-boss, through those ten bosses (with three hierarchical layers). If, however, a manager does not handle more than five subordinates, four hierarchical levels are needed. Because in the latter case each manager can spend more time with each subordinate, control at each hierarchical level is likely to increase. However, more hierarchical layers imply more cross-layer information garbling. This is the key trade-off between span of control and hierarchical layering. Depending on the values of the within-layer and the across-layer garbling factor, the net effect can go either way: it can be negative or positive. If the within-layer garbling factor (caused by enlarging the scope) is higher than the across-layer garbling factor (caused by imperfect vertical communication), then increasing the number of hierarchical layers will alleviate control loss, and vice versa.

Williamson continues by developing a formal model in which he demonstrates that the plausibility of his central thesis that "the cumulative effects of control loss are fundamentally responsible for limitations in firm size." This proposition follows straightforwardly from his conception of control loss due to information garbling across hierarchical layers. Furthermore, he shows that optimal firm size is reduced by a lower level of control, and increased by a higher level of control. ${ }^{7}$ The bottom line is that his model of the organization as a large Chinese whisper game clearly reveals that the intrinsic and inevitable imperfection of human communication implies important scale diseconomies that went, perhaps surprisingly, largely unnoticed in post-1967 organizational economics.

Before turning to a dynamic version of this logic, we first briefly summarize Williamson's (1967) formal model. We denote control between hierarchical levels $y$ and $y+1$ as $\alpha_{y}$, the number of employees as $N$, and the scope of each manager as $s$. The number of hierarchical layers, $n$, then equals ${ }^{s} \log N+1$. Cumulative control is symbolized by $A$. Then,

$$
\mathrm{A}=\prod_{y=1}^{s \log N} \alpha_{y}
$$

In order to simplify the model he was developing, Williamson assumed that control loss was equal for each additional hierarchical level. In that case, when ${ }^{s} \log N$ equals $n-1$, naturally, $\mathrm{A}=\alpha^{n-1}$. The result is that control loss becomes a power function of the number of levels, being equal to $1-\alpha^{n-1}$.

\footnotetext{
${ }^{6}$ The signal detection literature, and specifically Wickens (2002), could very well offer additional insights into optimizing the number of subordinates. The current article concentrates on the other dimension of the problem-i.e., vertical communication.

${ }^{7}$ Calvo and Wellisz (1978) "show" that "limitations of firm size by loss of control across hierarchical levels depend crucially on the nature of the supervision process." If the employees cannot identify the times at which their performance is monitored, there is no limit imposed on the firm size by the extensiveness of the hierarchical structure." Only through brave additional assumptions, following a conventionalist strategem (Popper 1963, p. 48), can this statement be maintained. The theory is mathematically refuted by Camacho and White (1981).
} 
The basic model now contains the following variables:

1. $s=$ Span of control (the number of employees a supervisor can handle effectively);

2. $\alpha=$ Fraction of work done by a subordinate that contributes to objectives of her supervisor $(0<\alpha<1)$, or a compliance parameter;

3. $N_{i}=$ Number of employees at the $i$ th hierarchical level;

4. $n=$ Number of hierarchical levels (the decision variable);

5. $P=$ Price of output;

6. $\quad w_{0}=$ Wage of production workers; $w_{i}=$ wage of employees at $i$ th hierarchical level $=w_{0} \beta^{n-i}(\beta>1)$;

7. $r=$ Non-wage variable cost per unit output; $Q=$ output $=\theta(\alpha s)^{n-1}$;

8. $R=$ Total revenue $=P Q$; and $C=$ total variable cost $=\sum_{i=1}^{n} w_{i} N_{i}+r Q$.

Williamson models net revenue to be

$$
R-C=P(\alpha s)^{n-1}-w_{0} \frac{s^{n}}{s-\beta}-r(\alpha s)^{n-1} .
$$

As long as $\alpha<1$, the second derivative is negative (for details, see Williamson 1967 , p. 129). Setting the first derivative equal to zero, we can conclude that there exists a rational and positive number $n^{*}$ that would result in maximum net revenue. When the number of hierarchical layers increases above that level, net revenue will diminish. With this model, Williamson has demonstrated the plausibility of his central thesis: cumulative effects of control loss are fundamentally responsible for limitations to firm size. Additionally, he convincingly argues that optimal $n^{*}$ increases as $\alpha$ increases (and, we would add, decreases as $\alpha$ decreases). In fact, if $\alpha$ decreases sufficiently optimal $n^{*}$ becomes 1 , and the raison dêtre of the firm disappears. Taking Williamson's (1967) model as our steppingstone, we next introduce a dynamic interpretation of the uncontrollability notion.

\section{The dynamics of control}

Stating that Williamson considered control to be fixed would be a misquotation. He does indeed suggest that there is some variation, and he even develops a model in which this compliance factor is expressed as a function of the average span of control. However, Williamson's model implicitly assumes that this factor is staticthat is, the extent of information garbling is not affected by time. We will now discard this assumption in order to investigate the dynamics of control, instead of the optimality of a certain firm size. In so doing, we give center stage to a dynamic conception of control loss. Control loss, reflected in a decrease of Williamson's control factor $\alpha$, can be caused by many circumstances and many types of behavior. Most of these can either be avoided or repaired, or both. We are not concerned with such avoidable or repairable causes of control loss. Rather, we develop a simulation model that describes a particular cause of control loss that eventually-always and inevitably, however long it may take-generates uncontrollability. Being 
theoretical, and a gross simplification, the model does not prove anything. Being plausible, though, our model offers a rationale for our central conjecture: in the long run, the uncontrollability of all organizations is both inevitable and irreparable. Our model focuses on one link in the chain of command. As stated earlier, control loss is strictly cumulative across hierarchical layers, and there is no systematic compensation. Therefore, the description of the dynamics of control between two adjacent hierarchical layers can be extended to loss of control between the head of the organization and the shop floor.

In order to take appropriate decisions, a manager needs information. The more detailed the instructions $\mathrm{she}^{8}$ has to pass on to her subordinates, the more information she needs. She can limit the managerial information needed by extending the scope of operational decisions - that is, by delegating authority. The manager can diminish her dependence on particular agents or subordinates by, for instance, creating lateral information channels (Galbraith 1977, p. 111), both from the shop floor to the CEO and vice versa. It is one of the tasks of the manager to monitor lateral flows and to take the actions necessary to maintain and repair them, or to design the organization in such a way that these flows are optimal. This may be a complex issue, involving mistakes and learning, but it can be done-at least, in theory. However, our central premise is that whatever clever organizational designs, information technologies and process measures are introduced, there will always be information that has to be transmitted from the bottom of the organization to the top and vice versa. It is here where the unavoidable source of control loss, however minuscule, is located.

The Williamson model incorporates this argument through the essential $\alpha$ parameter. Information transmission imperfection, however Epsilon tiny, (i) will cause information demanded from the subordinate to be different from the real needs of his superior, (ii) will imply that the superior obtains less than perfect information from her subordinate, and (iii) will generate an imperfect perception of reality by the superior. All this causes her orders to be less than perfect to reach the intended goals and her requests for information less than perfectly covering her managerial needs. Therefore, even if the subordinate succeeds in obeying the instructions to the letter in minute detail (which in reality is never the case), control loss cannot be avoided, and $\alpha<1$. To further set aside other sources of control loss, we take the case where our model describes a "mature" and "sincere" superiorsubordinate relationship; "mature" being defined as the state in which the routines of an organization have already been developed and optimized, and "sincere" as the absence of any agency issues. At time $t=0$, when we start to trace the history of the organization, the superior therefore knows what information she needs at that time, and she recognizes that the agent will not cheat or shirk in any way. In a mature and sincere organization, appropriate routines are established, and the flow of information can be smaller.

We now need to translate the above model into a system that can be simulated. To start with, the processes involved are described in Fig. 1.

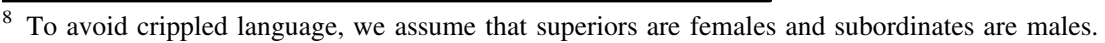




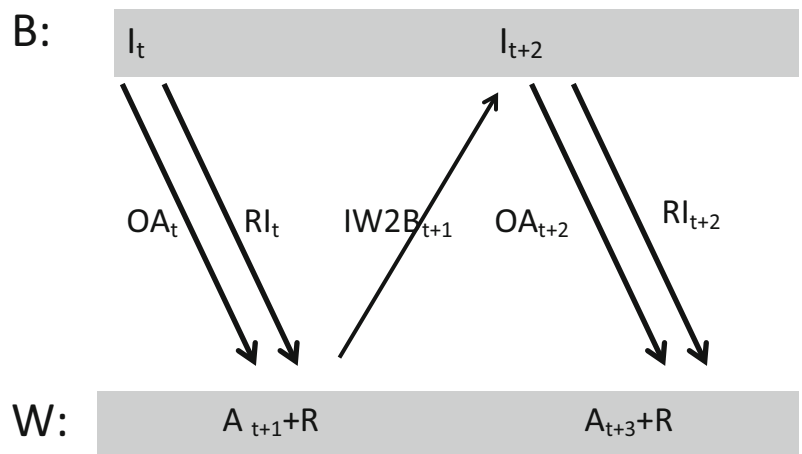

Fig. 1 Communication in a hierarchy. Top bar information available to the boss. Bottom bar information available to worker. Arrows messages between boss and worker. $O A_{t}$ orders to act at time $t . R I_{t}$ request for information at time $t . I W 2 B_{t}$ information provided by worker to boss at time $t$

The top layer represents the superior (B for Boss). The bottom line represents the subordinate (W for Worker). Being a link in the chain, the B in this figure would be the $\mathrm{W}$ in the link above and the $\mathrm{W}$ in the figure would be the $\mathrm{B}$ in the link below. OA (Orders to Act) indicates the instructions for action given by B to W. RI is a Request for Information. Information from Worker to Boss (IW2B) indicates information transferred from the subordinate to the superior. I indicates the information available to the superior and A represents the actions taken by the subordinate (including the instructions she gives to her subordinates at the next hierarchical level).

Formally, we can capture Fig. 1's essence as follows. As above, we introduce a number of simplifications, along the way, that make our simulation model conservative by isolating the impact of control loss from other potentially failureenhancing influences. As we will explain below, we will do so by imposing a series of simplifying assumptions that remove other sources of failure from our model setup. In so doing, we isolate the effect of information transmission imperfection from other potential sources of scale diseconomies or control loss. To focus on the essence, we have two people, the superior $(B)$ and the subordinate $(W)$. The superior is extremely intelligent, as the quality of her instructions is bounded only by the information available to her (another gross simplification). At time $t$, the superior has information $I_{t}$ available $\left(I_{t} \leq 1\right)$. If $I_{t}=1$, she can give instructions to $W$ that imply that if the subordinate follows them to the letter, the intentions of the superior will be completely fulfilled. If $I_{t}<1$, the instructions that $B$ can give are obviously less perfect. At time $t, B$ will give orders $O A_{t}$ to $W$. The appropriateness of these orders is assumed to be proportionate to $I_{t}\left(O A_{t} \propto I_{t}\right)$.

However, there is always some "noise" in communication. We therefore include a random garbling factor $g_{t}$. So, for ease of interpretation, we now have reformulated the control parameter $\alpha$ in the Simon-Williamson model as $1-g$ : the higher $g$, the more imperfect is the transmitted information. We assume that 
$\left(1-g_{t}\right) * O A_{t}$ is understood by $W$. Without any orders, $W$ will do his chores, $R .^{9}$ Because $W$ is a most obedient employee, his additional actions, $A_{t+1}-R$, closely follow his understanding of the orders $A_{t+1}-R=\left(1-g_{t}\right) * O A_{t} \propto\left(1-g_{t}\right) * \mathrm{I}_{\mathrm{t}}$. If no garbling takes place $(g=0)$, and if the availability of information is perfect $\left(I_{t}=1\right)$, the actions will also be perfect $\left(A_{t+1}=1\right)$. Then, control, as defined earlier, is $100 \%$.

$B$ knows that she will have to give orders again in $t+2$, and that she then will need information to give adequate orders. She therefore requests information, the adequacy of which is defined as $R I_{t}$. A perfect request would be $100 \%$. However, the information available to her is not perfect, and the adequacy of her request is proportionate to that knowledge. Therefore, $R I_{t} \propto I_{t}$. However, because $B$ realizes that things can happen at the level of $W$ of which $B$ is ignorant, she has arranged that $W$ will provide her with some extra information that $W$ considers relevant. In addition, $B$ will demand the information she needs to provide standard data for management information systems (cash in and outflows, out-of-pocket costs, store data, et cetera). These data are also available for management purposes, especially if they arrive in time to take appropriate action. Together, these data are included as $r r$.

$W$ is more than willing to provide whatever is requested, according to what he understands $B$ wants to know, but again we encounter the random garbling factor $g_{t}$. So here we have another simplifying assumption: the subordinate is completely honest, implying that willful manipulation or shirking will not occur. Again, if this assumption is omitted, control loss will increase. The adequacy of his answer is defined as $I W 2 B_{t+1}$ (Information provided by Worker 2 (to) Boss). Because his information can never be more than perfectly appropriate, $I W 2 B_{t+1} \leq 1$. He provides the answers

$$
I W 2 B_{t+1} \propto \min \left[R I_{t}^{d} *\left(1-g_{t}\right)+r r, 1\right]
$$

Of course, raising $R I$ to a higher power must be justified. When orders are nearly perfectly appropriate, possible slight gaps are easy to fill in. One of the conclusions that can be drawn from Bartlett's (1920, 1932), Alper and Korchin's (1952, p. 26) and Tresselt and Spragg's (1941) experimental work is that the less realism is experienced by the receiver, the higher the distortion. The relationship between the appropriateness of orders and their fulfillment is therefore not linear. Choosing a relationship with a higher exponent than 1 -for instance, $d(d>1)$ - is one way to incorporate this insight into our model. The quality of the information is garbled: $I_{t+2}=\min \left[I W 2 B_{t+1} *\left(1-g_{t+1}\right)^{d}, 1\right]$. The superior now gives her operational instructions based on the information she received. Their adequacy is $O A_{t+2} \propto\left(1-g_{t}\right) * \mathrm{I}_{\mathrm{t}+2}$. Again, the random information garbling factor is encountered. Assuming $I_{t}$ to be irrelevant for the decisions to be taken at $t+2$ (this is another simplification, for the sake of clarity), we can now repeat the cycle.

\footnotetext{
9 There exist interesting parallels between the determination of these chores within an organization and what Kornai (1973) describes as "autonomous control" in society as a whole. However, investigating these parallels would broaden our enquiry too much.
} 
So, from the above, the simulation model is based on the following six building blocks:

1. Coefficient $1-g_{t}$ is the "noise effect" in the communication $R I_{t}$ and $O A_{t}$ from superior $B$ to subordinate $W$ and vice versa $\left(I W 2 B_{t}\right)$. The coefficient $m g(t)$ represents an upper bound for precision in information transmission. We assume $g_{t}, m g_{(t)}[0,1]$ and $g_{t}=1-\min ([(1.5-m g) e+m g, 1])$, where $e$ is a random number drawn from a uniform distribution between 0 and 1 .

2. $I W 2 B_{t+1}$ is the adequacy of the information to $B$ at time $t+2$, with $I B 2 W_{t+1}$, $[0,1]$. A value of 1 means "perfect information" and $I B 2 W_{1}=1$ is the initial condition. So, we start with perfect information, initially.

3. $W$ receives $O A_{t}=K_{1} * \mathrm{I}_{\mathrm{t}}$, with $K_{1}=1 . O A_{t}$ might be interpreted as the "appropriateness" of the orders given to $W$.

4. $W$ takes total actions $A_{t+1}+R=\left(1-g_{t}\right) * A O_{t}+R$.

5. $B$ requests $R I(t)$ information from $W . R I_{t}=K_{2} I_{t}$, with $K_{2}=1$. The information that $B$ receives at time $t+1$ is $I W 2 B_{\mathrm{t}+1}=\min \left[\left(1-g_{t}\right)^{d} \mathrm{RIt}+r r, 1\right] . d$ is the distortion factor, for which in the model we simulated 1.2. Coefficient $r r$ is the extra information $B$ asks from $W$.

6. Information available to $B$ at time $t+2$ is $I_{t+2}=\min \left[I W 2 B_{t+1}\left(1-g_{t}\right), 1\right]$. From here, the next cycle starts.

In non-formal language, the model's process can be described as follows. In order to give appropriate instructions to her subordinates, a superior must obtain relevant and veracious information. A significant part of this information must be obtained from her subordinates. A superior will therefore regularly instruct her subordinates to provide her with the information that she regards as pertinent to the decisions she is about to take. Of course, the relevancy of her request will depend on the quality of information the superior already has. Her instructions will always be garbled, even if this garbling is only slight. And the subordinate's understanding of the requests will never be perfect, always subject to at least minor distortion. Assuming, however, that there are no agency complications, the subordinate will give the information he deems relevant. He may even give some additional information, or adapt the superior's instructions to his own ideas of relevancy. Again, during the process of transmittal of the requested information, some distortion-however tiny-will occur. Alterations can consist of omission, addition and content change.

At that moment, the superior's view of reality will undergo some distortion. She will lack information essential for the decisions to be taken, and part of the information she believes she has will be erroneous. This distortion will not always be recognized by the superior, and will therefore not be corrected. The relevancy of the requests for information from the subordinate will suffer. In earlier stages of our research, we believed that this was eventually sufficient to cause uncontrollability. We assumed the quality of the information provided by the worker to his boss was linear to the quality of her requests. Interestingly, while calculations showed variations in control, uncontrollability did not appear. In our thinking, this is not realistic and we therefore looked for improvements of our model that would increase its realism. 
One of the conclusions that can be drawn from Bartlett's (1920, 1932) experimental work is that the less realism is experienced by the receiver, the higher the distortion. This was corroborated by Tresselt and Spragg (1941). In an experiment of serial reproduction, the subjects were first "primed" with information to induce various "mental sets". These mental sets significantly influenced the amount and the direction of the distortion of the information initially provided. Alper and Korchin (1952, p. 26) find that "Much remembering behavior is motivated by a need to make sense of events past and present, to fit past events into a contemporary system of meanings." And as we have noted earlier, remembering is an essential link in the process of reproduction. We incorporated these observations into our model by changing the linear relationship between the quality of the information provided by the worker to his boss to the quality of her requests in one in which the relationship is exponential (with a power of 1.2; see above). This changed the behavior of the model drastically. In the final version of our model, one can indeed observe that at a certain point a vicious circle is launched in which the relevance of the information requested, the veracity and relevance of the answers, and the congruence between the superior's knowledge and reality all start to deteriorate, with this process of deterioration even accelerating over time. The operational instructions the subordinate receives become less and less accurate and appropriate, and the fraction of the intentions of a superior effectively satisfied by the subordinate will become negligible. The organization is now failing.

Our model conservatively reflects the logic implied by the Williamson argument of information transmission imperfection. The core of the simulation model is a stochastic logistic equation. We simulated with the model to explore the consequences of information transmission imperfection in the short and long run. Here, for the sake of brevity, we only report a random sample of simulation outcomes (the Matlab program is presented in the Appendix). A graphical presentation of the result after ten runs is given in Fig. 2, in which each line represents a run. A run simulates a sequence of 100 decision periods. The outcome

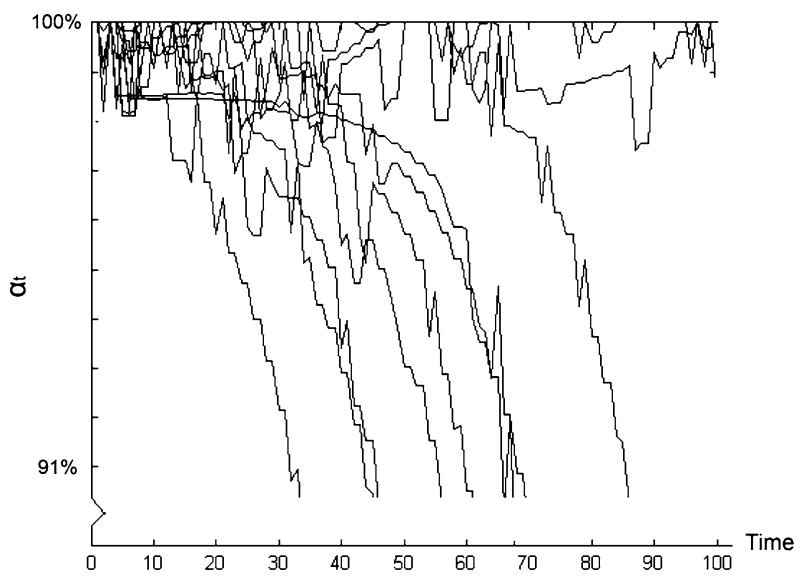

Fig. 2 Dynamics of organizational control loss 
of interest is the extent to which information is garbled, which ultimately determines the degree of control loss.

In eight runs, control deteriorates suddenly, quickly and permanently, with the timing of the collapse being completely random. In two runs, control continues to hover at a high level. In the long run, control will inevitably deteriorate in this pair of cases as well, though, as was confirmed by extending the simulation run beyond 100 decision periods. We have already seen how Williamson noted that the optimal $n$ (the number of hierarchical layers) increases as control increases. The opposite is also true. Optimal $n$ decreases as control decreases. When $\alpha$ falls sufficiently, the optimal number of hierarchical layers will drop to 1 . Optimality is reached by folding the organization. The organization fails, in the end, and does so inevitably. Clever procedures, policies and technologies can postpone failure due to control loss, by bringing $\alpha$ closer to 1 , but can never prevent this unhappy ending, as $\alpha=1$ is incompatible with the fundamental fact of human information exchange imperfection.

Evidently, there exist some interesting parallels between the properties of the model developed here, and those developed earlier in the study of nonlinear dynamic theory. For instance, Heiner (1989) demonstrates that by partial adjustment in optimizing behavior a certain level of stability is attained. In our model, performance is initially also stable at a high level, but a sort of stochastic time bomb is included in the model that causes control to drop drastically at an unpredictable moment. Stability is eventually attained again, but at a low level. If Heiner had included "a long tail catastrophe" in his model (a realistic inclusion, as we argue here), the parallels would have become more visible.

\section{Non-hierarchies}

A second limitation of Williamson's treatment is that his model describes strictly hierarchically structured organizations. We therefore move our attention to the other extreme end of the spectrum: worker peer group associations. As will become clear below, such groups are an interesting theoretical test case for Williamson's and our argument, as hierarchical information garbling is absent by definition. Williamson (1973, p. 321) defined these as groups of people engaged in collective and usually cooperative activity, providing for some type of income arrangement, but not entailing subordination. Such a group may arise for associational reasons, because of risk-bearing advantages and/or to mitigate the effects of indivisibilities (for instance, in the costs of back-office or of branding activities). They are vulnerable to free-rider abuses, whether caused by diverging aptitudes or attitudes. In addition, the economies attributable to indivisibilities can be difficult to achieve in the absence of any concentration of authority. Traditional professional partnerships are excellent examples in the real world, as well as "tolong-menolong" small-scale farmers in many poor communities.

\footnotetext{
10 This is Malaysian. Verbatim translation: "to help and be helped". For instance, "you work in my field today and I work in your field tomorrow".
} 
With individuals not being subordinate to one another (only "to the group"), each individual by definition has considerable leeway in deciding what action to take. So, the garbling of instructions that we encountered in Williamson's model is absent. This does not mean that no communication should take place-quite the contrary. In order to achieve any benefits, coordination must be achieved, in one way or the other. For instance, a lawyers' partnership increases the effectiveness of its members only when they have an idea of each other's specific expertise and current workload. It is only then that they can make use of each other's slack, and that they can make use of other partners' knowledge when a case raises questions outside one's own specific field. In relatively small outfits, this knowledge is simple to acquire. But when the group becomes larger, this can become difficult, not so much because - at least when a cooperative spirit reigns - questions and answers are not straightforward, but because one must first find out whom to ask what. After all, the organization contains $N$ ! "edges"- a figure that increases sharply with the size of the organization.

Under these circumstances, the advantages of a communication "hierarchy" are reasonably obvious (Williamson 1973, p. 322). Whether intentionally or spontaneously, a participant is "appointed" who collects and distributes the relevant information as and when required. Because this activity does not include any processing of information (she even can be a secretary or a socially active bookkeeper), her scope can be much larger than that of a supervisor. But in other ways, the structure closely resembles the hierarchical organizational design described by Williamson (1967). To emphasize that subordination plays no role, we arranged the "informational organization chart" of worker peer group in two semi-circles, as visualized in Fig. 3. It describes a group for which the information

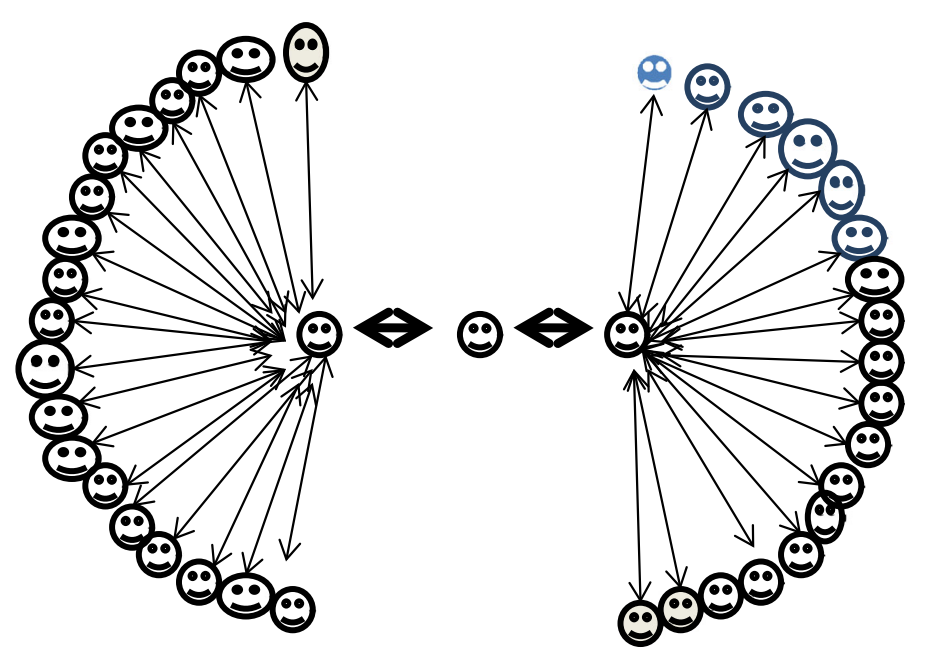

Fig. 3 Communication in a non-hierarchy without a center. Arrows requests for information and information flows, respectively 
flow runs through two layers, because one information officer can no longer cover the whole group.

Information flows between the center and the workers initially follow more or less the same path as that between the manager and the worker described earlier. However, additionally, the worker regularly will make enquiries at the center, in order to enable her to make the decisions necessary for her activities. This flow is described in Fig. 4.

The dynamics of this flow resemble that between a subordinate and a superior. Again, information is requested, and the request is garbled, however slightly; a response is made and arrives slightly distorted. The recipient of this information bases a new enquiry on the slightly garbled information she received earlier. And so on, and so forth. To avoid a repetition of our earlier analysis, it suffices to state that the relevance and veracity of this information can, again, be described using a simulation model. The core of the simulation model is, again, a stochastic logistic equation. The result will be the same, only in this case the problem is not one of vertical control loss, but rather of what may be coined horizontal control loss (Nieto Morales et al. 2013). The worker is her own manager, and therefore always is fully in control. The problem is that she unknowingly loses touch with the remainder of the group, and that the remainder of the group unknowingly loses touch with her. The advantages of cooperation disappear, the reason being that all human communication, whether vertically or horizontally transmitted, is imperfect, as was already clear from Bartlett's $(1920,1932)$ early work.

We realize that up to now this exercise is only theoretical. Before a peer group reaches the size where these mechanisms become significant, it is likely to have been reorganized along much more hierarchical lines, with "workers" becoming more subordinated to coordination structures involving "bosses". The main reason is that peer groups become more vulnerable for free-rider problems and decision processes more inefficient once a peer group has reached a certain size. As we will show in the next section, this does not mean that this exercise has no practical application-quite the contrary.

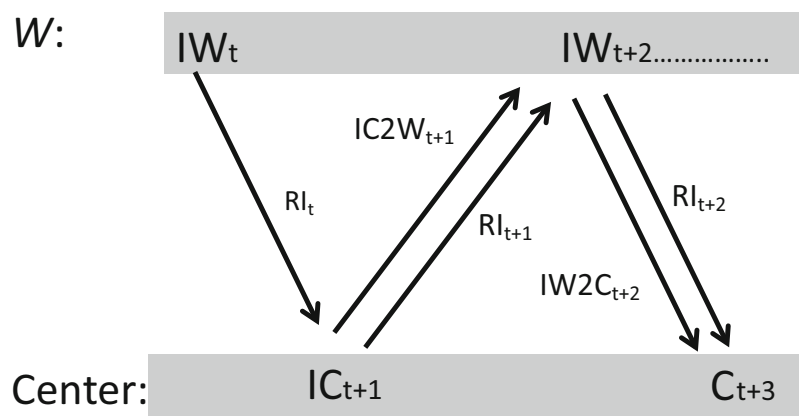

Fig. 4 Communication in a non-hierarchy with a center. Top bar information available to worker. Bottom bar information available at the center. Arrows messages between center and worker. $R I_{t}$ request for information at time $t$. IC $2 W_{t}$ information provided by center to worker at time $t$. IW2 $C_{t}$ information provided by worker to center at time $t$ 


\section{From simple models to complex realities}

In real life, organizations are a heterogeneous network of strictly hierarchical and lateral authority structures combined with vertical and horizontal (non)authority lines, and with areas and dimensions in which members of the organization act with differing degrees of autonomy. In other words, an organization is a heterogeneous mixture of areas and dimensions that can be characterized as more and less hierarchically organized. For instance, the "simple rules" approach described by Eisenhardt and Sull (2001) provides considerable leeway at lower hierarchical levels. However, as their example of Enron clearly demonstrates, higher management (and the regulatory authorities!) must still be able to monitor whether these rules continue to be appropriate. Because we have just demonstrated that both extremes-hierarchical and non-hierarchical—are both subject to control loss, the conclusion is justified that all organizations, whether they are organized as strict hierarchies or not, will inevitably slip away into uncontrollability at some point in time. This ultimate state of control loss may sometimes-or perhaps often-be postponed, but cannot be avoided, in the (literally) end. Hence, Williamson's limitation of a hierarchical organization has been relaxed.

For the sake of clarity, we assumed in the hierarchical model that the superior is completely dependent on hierarchical information flows from below-that is, from information provided by her subordinate. This is a simplification, as there are often additional sources of information. Therefore, using multiple sources of information, and careful checks and cross-checks, may help to postpone the emergence of uncontrollability by increasing $\alpha$ in our model. For instance, in the "continental" business model (contrary to its Anglo-Saxon counterpart), work councils can, if given half a chance, provide an invaluable flanking informational structure, invaluable both for management and for workers (van den Berg et al. 2011). This was an important motive why, for instance, the Dutch branch of Unilever positively cultivated its works councils, both at the plant and at the national level. ${ }^{11}$ The potential of such a flanking informational structure is further enhanced by organizational democratization (de Jong and van Witteloostuijn 2004).

In future research, the effect of these and many other uncontrollabilitypostponing devices, such as modern information technologies, can be studied in greater detail. However, introducing such additional sources of information now would make our model more complex without affecting the pattern of results. To assume that information cannot be perfect, whatever the quality of the other sources of information or technologies of exchange that the manager can employ, is very plausible, and standard in organization sciences, including organizational economics. In fact, without an assumption of information imperfection, organizational economics would be an empty shell. We would then be back in the frictionless economic paradise of Walrasian general equilibrium perfection. It would then be as if neither Coase (1937) nor Williamson (1967) would have explained so

\footnotetext{
${ }^{11}$ Personal communication Henri de Bijll Nachenius, a former national industrial relations officer of Unilever Nederland. See also Brezet and de Bijll Nachenius (1998, p. 132).
} 
convincingly and lucidly that assuming such a perfect world implies assuming away organizations to start with.

To illustrate that the phenomenon of "uncontrollability" is not just a figment of our theoretical modeling or our academic imagination, we would like to briefly discuss a few real-life examples that, of course, cannot prove anything, but that nicely bring our argument to life. First, a short citation from recent history may be instrumental. Lewis (2010, p. 174) cites Steve Eisman "I'd go into meetings with Wall Street CEOs and ask them the most basic questions about their balance sheets. They didn't know. They didn't know their own balance sheets." And on page 254, he cites John Gutfreund, former CEO of Salomon Brothers, as saying "I didn't understand all the product lines and they don't either." We all know how this ended. Lehman Brothers went into bankruptcy, its remains inserted into a few surviving financial institutions in the US and elsewhere, and Salomon Brothers disappeared into the black hole of the Citigroup.

Uncontrollability does not mean that control is zero, and it does not automatically imply that the effectiveness of the organization will disappear completely. In the case of control being $100 \%$, all the intentions of the boss are effectively and fully satisfied by the worker. In other words, the actions of the worker are bounded by the intentions of the principal. In case of uncontrollability, the actions of the worker are bounded by the inappropriate instructions given and by the monitoring, reward and penalty options still feasible and operational. Within these much wider bounds, personnel will follow their own private inclinations. Rational but loyal workers, knowing that information available to management is garbled, will act 'in the spirit of the orders' they receive-i.e., show 'intelligent' effort. However, because their understanding of the complete picture is deficient, this effort to adapt instructions can easily lead them in the wrong direction. This can often be observed in the tradeoff between quality and quantity, when workers believe that the interests of the firm are best served by increasing quantity (knowing that quality will suffer), while management realizes that lack of quality is causing a loss of customers. Inappropriate motivation, unknown to management, can also be a problem. Many workers have selected their job because they like what they end up doing. A bus driver likes to drive his bus, albeit preferably in his own time and according to his own schedule. An uncontrollable public bus company will therefore still see its buses driving around. But the bosses do not know why buses are late, why so many buses remain idle in the workshop, why passengers are treated atrociously by some drivers (nasty characters) or courteously by other drivers (nice chaps who love to interact with people), why some bus-stops are ignored, and why productivity is so unacceptably low and costs are so excessively high. This is similar to another systematic and classic analysis of a certain type of uncontrollable organisations, or “organized anarchies": Cohen et al.'s (1972) classic garbage can model.

Often control is different, in degree and in the way executed, in different dimensions. An organization's productive activities can be completely out of control, while its cash management is still in order, and it can still comply with a rigorously hard budget constraint. If output is not considered to be essential, the budget will be kept in place and output will be allowed to sink. Anybody can provide many examples. Just to illustrate the point, the following case is revealing. 
In the 1980s, one of this article's authors encountered a soil survey project of the United Nations in Sierra Leone. The project had been planned on the basis of the UNDP providing (expensive) expatriate personnel, while the local government was to provide transport. The local government did not meet its commitments and no transport was available. After a few months of deskwork, all work was forced to stop; but after 2 or 3 years, the experts were still there. No work of any value could be done (except helping this author to a number of maps he needed for his own work). It is a mystery what hierarchical level in the UN was informed of this waste of money, but someone decided not to inform his superior. In any case, the information was lost and no action was taken to stop this "counter-intentional expenditure". However, planning and budget were probably completely in order. The author (a former employee of UNDP himself) often observed how strictly and controlled expenditure was managed. At the top, nobody knew that output was absent. Expenditure continued until the money was spent. As a post-script, therefore, a slight differentiation should be added. Control can have various dimensions. An organization may experience uncontrollability in one dimension, whilst still being completely in control in another.

As a second illustration we could mention British Petroleum (BP) in the 2000s. There is every indication that financial control of the oil company was in order (accountants made no reservations in approving the annual report). Management knew how much money was being spent on what and how much profit was made where and with what products. At the same time, BP management lacked knowledge on the safety of its operations. Disasters were waiting to happen, and eventually two disasters did happen: Texas oil refinery and Deepwater Horizon. Even if it was narrowly pursuing profits and no environmental or humane considerations had entered into its equations, had BP management been in control it would have eliminated these risks. BP narrowly escaped bankruptcy. BP was lucky, but many other organizations were not, as we could illustrate with reference to banks in the time leading to the 2008 financial crisis.

\section{Conclusion}

Organizational failure is by no means an understudied phenomenon. Quite a number of internal and external causes have been identified, and studied in great detail. By analyzing the dynamics of the concept of "control", an additional internal cause of failure is introduced with far-reaching consequences. We believe that we have identified a specific source of organizational control loss that-once a certain level is reached — cannot be repaired, curbed or predicted, and therefore cannot avoided. We introduce the term uncontrollability to describe this condition, defined as the situation in which control has fallen below a certain level such that the principal cannot take any effective remedial action because, for lack of sufficiently accurate and relevant information, adequate diagnosis is not possible, implying that ultimately each and every organization is bound to fail, falling victim of irreversible uncontrollability. The words "ultimately bound to" and "irreversible" can be translated into a more formal language as $\lim _{t \rightarrow \infty} P_{t}\left(\alpha_{t}<\min \right)=1$ in which "min" is 
the minimum level of control below which the organization has become uncontrollable. Because "in the long run we are all dead", as Keynes (in)famously stated in 1923, this claim is immune against direct falsification. However, many links in the chain of the argument are susceptible and a number of them have already undergone empirical testing (see van der Mandele 2006, pp. 95-112). We show that this vulnerability to uncontrollability persists, even in a completely stable environment.

A metaphor that illustrates this key logic is the shattered windshield of a car. Even the great Michael Schumacher, the world champion Formula I racing for many years, would not be able to keep his car on the road when his car's windshield would be shattered. Similarly, organizational uncontrollability is inevitable in the long run. Even though chances of the occurrence of uncontrollability can be minimized (for instance, by avoiding driving on newly graveled asphalt roads, in the Schumacher example), it is inevitable and irreversible. When exactly organizational uncontrollability will arise cannot be predicted, in the same way as it cannot be predicted when a windshield will shatter. However, if our model mirrors reality (and we have no reason to assume it does not), we can argue that it will happen, inevitably. It can be postponed, but not avoided-thus follows our conjecture that uncontrollability is haphazard, inevitable and irreparable. In future work, after further developing our model, more detailed and systematic computer simulations can be run to explore the effect of different uncontrollability-postponing managerial interventions.

We derive this result without imposing any of the assumptions so typical for organizational economics. That is, in our model, we have not introduced the assumption that agents are guided by self-interest. Conflict of interest is absent, and agents behave honestly in the interest of their principals. In our "Bartlettian" world of imperfect communication, we only have willing, hard-working and altruistic people, all trying to do their utmost best to serve the interests of their boss and organization. Introducing additional elements of imperfection in the model, from free riding and shirking to corrupted and self-serving behavior, would further aggravate the diseconomies that ultimately trigger failure. Seen like this, our narrative is complementary to the established stories about organizational decline and failure that can be found in the literature.

The essence of imperfect human information exchange for the theory of the firm was largely missed by later organization theory, particularly organizational economics. For instance, Calvo and Wellisz (1978) and Qian (1994) equate a high level of control with a high level of effort, which is standard in agency theoryinspired organizational economics. In formal vocabulary, we could say that it is not the length of the vector, as much as the length of its perpendicular projection onto the principal's utility vector. In other words, control is not only a question of the effectiveness of the whip, but also of appropriate and effective use of the reins. In their use of the term "control", Maskin et al. (2000), e.g., also miss an essential dimension of Williamson's (1967) use of the term, believing that control is achieved when units are monitored through "yardstick competition". However, Williamson's control involves monitoring the appropriateness of the yardsticks as well.

Our logic squarely follows Coase's (1937), Simon's (1951) and Williamson's (1967) classic contributions to the theory of the firm. However, their and our emphasis on authority deviates from mainstream organizational economics. As Hart and Moore (2005, p. 679) point out, by and large, existing literature does not analyze hierarchy in 
terms of authority. Papers by Aghion and Tirole (1995), Baker et al. (1999) and Rajan and Zingales (2001) are exceptions. We believe that this emphasis on authority is essential in the study of organizational decline and failure, as is clear from the huge leadership literature (e.g., Judge et al. 2002; van Vught et al. 2008), particularly to the extent that leadership is linked to group or organizational performance (see Boone et al. 2005). The reason for this is that, by doing so, the imperfect nature of human communication can be brought back into the heart of the theory of the firm. ${ }^{12}$

Our control loss argument is complementary to other antecedents of organizational malfunctioning as identified in organization theory. For instance, we assume that the boss is bright, that the worker is honest, and that both are in a happy state of goal congruence. Assuming the boss is not that bright (which would significantly increase the realism of the model) merely aggravates control loss, as would the assumption that the subordinate is not completely honest, loyal and obedient, engaging willful manipulation or shirking (ditto). In our model, nowhere does a lack of cognitive abilities, neither on the side of the superior, nor on that of the subordinate, enter into the equation. In the same vein, we assume that there is full goal congruence between superior and subordinate. As such, our analysis diverges from classical agency theory. In so doing, we focus on the effect of imperfect information exchange. Any extra impact from other types of imperfection can easily be introduced, which would only aggrevate the inevitability of uncontrollability.

Our argument suggests that an information exchange imperfection perspective can and should enrich the theory of the firm (cf. Galbraith 1977). If we accept the fundamental fact that human information exchange can never be fully accurate, whatever clever monitoring devices are installed and whatever sophisticated information technologies are implemented, due to the intrinsic and unavoidable imperfect working of the human brain, then any theory of the firm is incomplete if the implications of this imperfection are not taken on board. In this paper, we offered a first exploration of possible implications, starting from Williamson's (1967) very insightful control theory of organizational size. Further work is needed to fully develop this information exchange imperfection perspective-e.g., to examine what managers and organizations can do to postpone the inevitable downsides of uncontrollability. For instance, in the literature regarding strategic delegation (see, e.g., Vickers 1985; Jansen et al. 2007), the implicit assumption is that the agent is fully aware of the intentions of the principal, implying an untenable assumption of perfect human information exchange. Relaxing this assumption is likely to reduce the acclaimed advantages of strategic delegation practices.

Open Access This article is distributed under the terms of the Creative Commons Attribution 4.0 International License (http://creativecommons.org/licenses/by/4.0/), which permits unrestricted use, distribution, and reproduction in any medium, provided you give appropriate credit to the original author(s) and the source, provide a link to the Creative Commons license, and indicate if changes were made.

\footnotetext{
12 However, even if authority is played down, control still remains relevant. For instance, Tannenbaum (1962, p. 237) defines a social organization as "an ordered arrangement of individual interactions. Control processes help circumscribe idiosyncratic behaviors and keep them conformant with the rational plan of the organization." Or Leifer and Mills (1996, p. 114), citing Etzioni (1961): "assuring that behaviors are oriented to organizational objectives is the central notion of organizational control."
} 


\section{Appendix}

\section{Matlab program simulating uncontrollability}

tic

$\operatorname{Matriz}(1: 1,1)=[0.003: 0.003: .003]$ '; \%rr values !!!!numbers should equal values to be tested!!!!! $\mathrm{mg}=0.98 ; 0.9$ Upper bound for precision. Beyond it there is noise. Try 0.4, 0.6, 0.8, 0.9 $\mathrm{K} 1=1$;

$\mathrm{K} 2=1$;

$\mathrm{R}=0$;

$\mathrm{d}=1-2$

Time $=100$;

$\mathrm{z}=1.1$;

TrialsPerCase $=100$;

NumberOfRuns = 10;

for $\mathrm{i}=1: 1$ :NumberOfRuns

AAverage $=$ zeros $($ Time, 1$)$;

IW2BAverage $=$ zeros $($ Time, 1$)$;

IB2WAverage $=$ zeros $($ Time, 1$)$;

for trials $=1: 1$ :TrialsPerCase

clear A IB2W IW2B OA RI g rr

$\mathrm{rr}=\operatorname{Matriz}(1,1)$;

for $\mathrm{t}=1: 1$ : Time

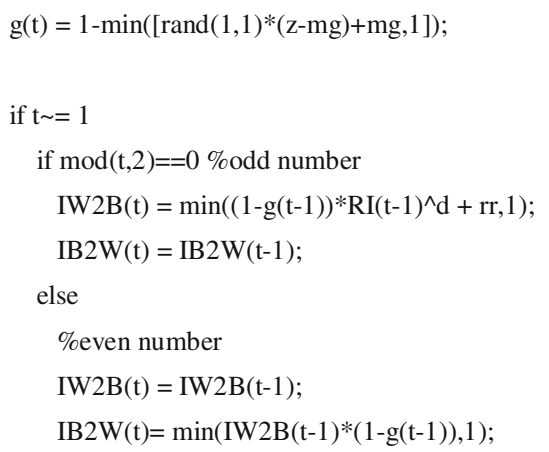




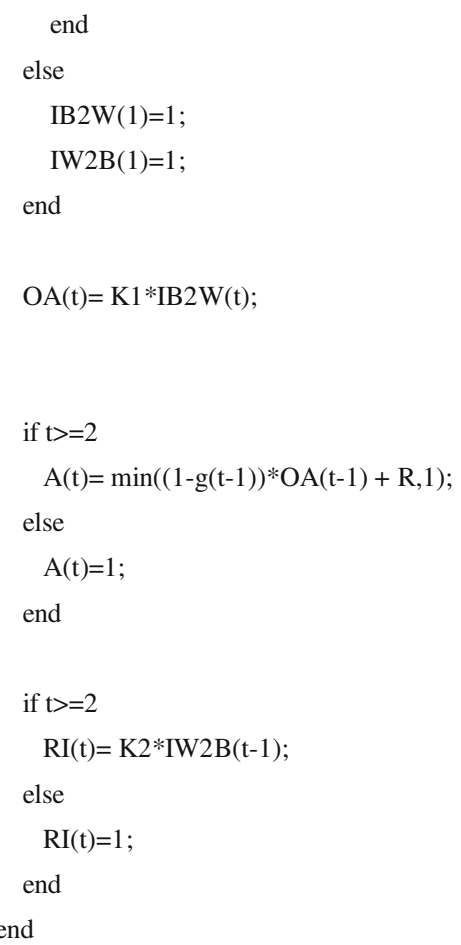

AAverage $=$ AAverage $+\mathrm{A}^{\prime}$;

IW2BAverage = IW2BAverage + IW2B';

IB2WAverage = IB2WAverage + IB2W';

end \%end for trials

AAverage $=$ AAverage $/$ TrialsPerCase;

IW2BAverage =IW2BAverage/TrialsPerCase;

IB2WAverage =IB2WAverage/TrialsPerCase;

Output $=$ [AAverage IW2BAverage IB2WAverage $]$;

nombre $=[$ 'Output' int2str(mg*100) '_. int2str(i) '.dat'];

save(nombre, 'Output' ,'-ascii','-tabs');

$\%$ subplot $(1,3,1)$ 


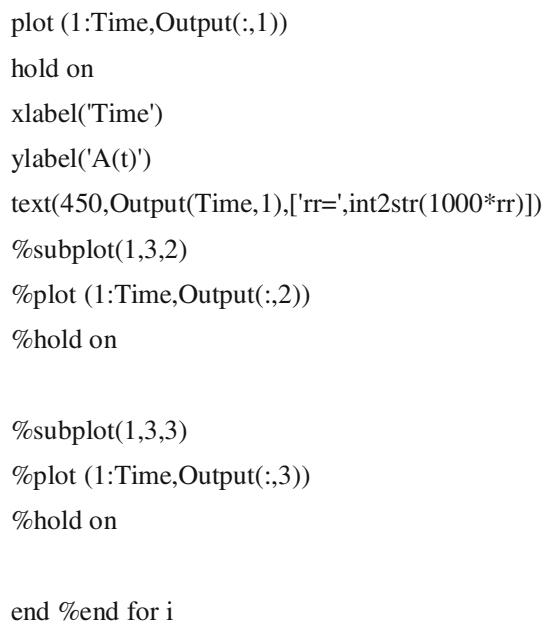

toc

\section{References}

Abell P (ed) (1975) Organizations as bargaining and influence systems. Heinemann, London

Abell P (1977) The many faces of power and liberty: revealed preference, autonomy, and teleological explanation. Sociology 11:3-24

Aghion P, Tirole J (1995) Some implications of growth for organizational form and ownership structure. Eur Econ Rev 39:440-455

Alper TG, Korchin SJ (1952) Memory for socially relevant material. J Abnorm Soc Psychol 47:25-37

Baker G, Gibbons R, Murphy KJ (1999) Informal authority in organizations. J Law Econ Organ 15:56-73

Bartlett FC (1920) Some experiments on the reproduction of folk-stories. Folklore 31:30-47

Bartlett FC (1932) Remembering. Cambridge University Press, Cambridge

Boone C, van Olffen W, van Witteloostuijn A (2005) Team locus-of-control composition, leadership structure, information acquisition, and financial performance: a business simulation study. Acad Manag J 48:889-909

Boulding KE (1966) The economics of knowledge and the knowledge of economics. Am Econ Rev $56: 1-13$

Brezet M, de Bijll Nachenius HJ (1998) In gesprek: 25 jaar Centrale Ondernemingsraad van Unilever Nederland 1973-1998 ("Talking: 25 years central works council of Unilever The Netherlands 1973-1998”). Unilever, Rotterdam

Calvo GA, Wellisz S (1978) Supervision, loss of control, and the optimum size of the firm. J Polit Econ 86:943-952

Camacho A, White WD (1981) A note on loss of control and the optimum size of the firm. J Polit Econ 89:407-410

Coase RH (1937) The nature of the firm. Reprinted in Coase RH, The Firm, the Market and the Law (1988). Chicago University Press, Chicago, IL

Cohen MD, March JG, Olsen JP (1972) A garbage can model of organizational choice. Adm Sci Q $17: 1-25$

De Jong G, van Witteloostuijn A (2004) Successful corporate democracy: sustainable cooperation of capital and labor in the Dutch Breman Group. Acad Manag Exec 18:54-66 
Downs A (1966) Bureaucratic structure and decision making. Research memorandum RM 4646 PR. RAND, Santa Monica

Eisenhardt KM, Sull DN (2001) Strategy as simple rules. Harv Bus Rev 79:105-116

Etzioni A (1961) Complex organizations: a sociological reader. Holt, Rinehart and Winston, New York Galbraith JR (1977) Organization design. Addison-Wesley, Reading

Hannan MT, Freeman J (1977) The population ecology of organizations. Am J Sociol 82:926-964

Hannan MT, Freeman J (1984) Structural inertia and organizational change. Am Sociol Rev 49:149-164

Hart O, Moore J (2005) On the design of hierarchies: coordination versus specialization. J Polit Econ 113:675-702

Heiner RA (1989) The origin of predictable dynamic behavior. J Econ Behav Organ 12:233-257

Jansen T, van Lier A, van Witteloostuijn A (2007) A note on strategic delegation: the market share case. Int J Ind Organ 25:531-539

Judge TA, Ilies R, Bono JE, Gerhardt MW (2002) Personality and leadership: a qualitative and quantitative review. J Appl Psychol 87:765-780

Keren M, Levhari D (1989) Decentralization, aggregation, control loss and costs in a hierarchical model of the firm. J Econ Behav Organ 11:213-236

Kornai J, Martos B (1973) Autonomous control of the economic system. Econometrica 41:509-528

Leifer R, Mills PK (1996) An information processing approach for deciding upon control strategies and reducing control loss in emerging organizations. J Manag 22:113-137

Levitt B, March JG (1988) Organizational learning. Ann Rev Sociol 14:319-340

Lewis M (2010) The Big Short: inside the doomsday machine. Allan Lane, London

Marris R, Mueller DC (1980) The corporation, competition and the invisible hand. J Econ Lit 18:32-63

Maskin E, Qian Y, Yu C (2000) Incentives, information, and organizational form. Rev Econ Stud 67:359-378

Miller D (1990) The Icarus Paradox: how exceptional companies bring about their own downfall. Harper Business, New York

Nieto Morales F, Wittek R, van Witteloostuijn A (2013) Managerial control loss and organizational change. Working paper. University of Groningen, Department of Sociology, Groningen

Popper KR (1963) Conjectures and refutations, Routledge Classics Edition 2002. Routledge, London

Qian Y (1994) Incentives and loss of control in an optimal hierarchy. Rev Econ Stud 61:527-544

Rajan RG, Zingales L (2001) The firm as a dedicated hierarchy: a theory of the origins and growth of firms. Quart J Econ 116:805-851

Roediger HL III, Meade ML, Galloc DA, Olsond KR (2014) Bartlett revisited: direct comparison of repeated reproduction and serial reproduction techniques. J Appl Res Mem Cognit 3:266-271

Simon HA (1951) A formal theory of the employment relationship. Econometrica 19:293-305

Sorge AM, van Witteloostuijn A (2004) The (non)sense of organizational change: an essai about universal management hypes, sick consultancy metaphors and healthy organization theories. Organ Stud 25:1205-1231

Stinchcombe AL (1965) Social structure and organizations. Rand McNally, Chicago

Stinchcombe AL (2001) When formality works: authority and abstraction in law and organizations. University of Chicago Press, Chicago

Tannenbaum AS (1962) Control in organizations: individual adjustment and organizational performance. Adm Sci Q 7:236-257

Tresselt ME, Spragg SDS (1941) Changes occurring in the serial reproduction of verbally perceived materials. Pedag Semin J Genet Psychol 58:255-264

Van den Berg A, Grift Y, van Witteloostuijn A (2011) Managerial perceptions of works councils' effectiveness in the Netherlands. Ind Relat 50:497-513

Van der Mandele HC (2006) Economic apoptosis and uncontrollability: a first enquiry into the concepts and their relevance for the market-government debate. De Uilen Publications, Harlingen

Van der Mandele HC, van Witteloostuijn A (2013) Free to fail: creative destruction revisited. Edward Elgar, Cheltenham, UK

Van Vught M, Hogan R, Kaiser R (2008) Leadership, followership, and evolution: some lessons from the past. Am Psychol 63:182-196

Vickers J (1985) Delegation and the theory of the firm. Econ J 95:138-147

Wickens CD (2002) Multiple resources and performance prediction. Theor Issues Ergon Sci 3:159-177 
Williamson OE (1967) Hierarchical control and optimum firm size. J Polit Econ 75:123-138

Williamson OE (1973) Markets and hierarchies: some elementary considerations. Am Econ Rev 63:316-325

Hugh van der Mandele is a Retired Economist. After his retirement, he did a Ph.D. on organizational uncontrollability at the University of Groningen in The Netherlands.

Arjen van Witteloostuijn is Full Professor at Tilburg University and Antwerp Management School. He has published in journals such as the Academy of Management Review, Academy of Management Journal, American Journal of Political Science, American Sociological Review, International Journal of Industrial Organization, Journal of International Business Studies, Journal of Public Administration Practice and Theory, Organization Science, and the Strategic Management Journal. 